\title{
SPATIAL ANALYSIS BASED HEALTH AND SAFETY RISK ASSESSMENT FOR LINEAR CONSTRUCTION PROJECTS
}

\author{
H. Atay ${ }^{\mathrm{a}}, \mathrm{G} \cdot \mathrm{Toz}^{\mathrm{a}}$ \\ ${ }^{a}$ ITU, Civil Engineering Faculty, 80626 Maslak Istanbul, Turkey - hasanatay@ hotmail.com, tozg@itu.edu.tr
}

KEY WORDS: GIS, Health and Safety, Linear Project

\begin{abstract}
:
This paper describes an on-going study that aims to develop a web-based spatial decision support system model for proactive health and safety management in linear construction projects. Currently, health and safety management is usually performed reactively instead of proactive management since hazard identification and risk assessment is mostly performed on paper based documents that are not effectively used at site. This leads to accidents and fatalities at construction sites. The proposed system automatically identifies the spatial risks according to the topographic and layout map of the site, project specification and health and safety regulations by means of spatial analysis. It enables the workers and management personnel to access the possible hazards and thematic risk map of any portion of the construction site for linear projects.
\end{abstract}

Finally, the described approach provides the proposed mitigation measures for the identified hazards. The developed system is expected to raise awareness in H\&S among workers and engineers, and increase participation of workers to health and safety management.

\section{INTRODUCTION}

\subsection{Construction Industry, Health and Safety (H\&S) and Geographical Information System (GIS)}

The construction industry is statistically one of the most hazardous industries in many countries (Salminen, 1995; SGK, 2007; BLS, 2009). Besides causing fatalities, construction accidents also increase costs, cause delays and damage the reputation of the contractors (Everett and Frank, 1996). British Health and Safety Executive (HSE) have been reported that cost of accidents in construction sector has become $3-6 \%$ of total project cost (HSE, 2009).

Construction safety is one of great concern for construction industry because of ranked low in the safety standards. Failure of managing construction safety may results in injuries, financial loss, human conflicts, and penalties. Thus, construction industry needs a tool that may help them to actively integrate safety and health measure into project planning. Therefore there is a need of development of a database, which solicits project specific data from the user and provides, as output, applicable safety control recommendations (Kartam, 1997).

Complex and vast amount of information available for a construction project requires a coordinated system that may help in integrating whole information together. With the advances in the field of information technologies, construction industry has started taking the advantages of some of these developments. GIS is a relatively new branch of such technologies for managing the spatial and non-spatial data. Database is the essential part of any information system employed for construction management so the usefulness of geographical information system need to be explored (Bansal and $\mathrm{Pal}, 2005)$.
GIS is a computer system for capturing, storing, quarrying, analysing, and displaying geographic data. GIS is a special class of information system, which can be divided into four components involving a computer system, GIS software, human expert, and the data (Lo and Yeung, 2002). GIS activity can be grouped into spatial data input, attribute data management, data display, data exploration, data analysis, and GIS modelling (Clark, 2001).

Health and Safety (H\&S) management is especially important for linear projects (e.g., pipeline or highway projects) due spatially dispersed nature of horizontally linear projects. In linear projects, the project site is not at a fixed location and multiple crews and sub-contractors perform jobs at various scattered points along a route which might be hundreds kilometres. Thus, it is a challenging task for site engineers and superintendents to follow up production closely and to identify $\mathrm{H} \& \mathrm{~S}$ risks. There is a need for identifying $\mathrm{H} \& \mathrm{~S}$ risks automatically at the job sites of such projects for proactive $H \& S$ management and planning.

\subsection{Motivation}

In many construction companies, H\&S departments operate on a reactive business management model due to a number of factors including minimal staff, limited budgets and an inadequate corporate safety culture (Mohamed, 2003). Lack of resources and support lead to H\&S departments that can only react to unmanaged hazards/risks rather than being proactive by assessing and mitigating risks before a problem or an accident occurs.

To develop a proactive H\&S management system, Saurin et al. devised a model to integrate safety into three hierarchical levels (i.e., long-term, medium-term, and short-term) of production planning (Saurin et al., 2004). In another research is a framework for a computerized safety and health knowledge 
intensive system that was integrated with current critical-pathmethod (CPM) scheduling software (Kartam, 1997). In this framework, extensive safety data and knowledge were coded and stored in a database system which was linked to other construction management files. However, in these studies, the $\mathrm{H} \& \mathrm{~S}$ data is hardcoded in the system and they do not dynamically use any geographic information from the site and represent it visually to the user.

Recently, GIS technology is being effectively used for route selection, feasibility studies, progress monitoring, asset management, and operation and maintenance management for linear projects (Luettinger and Thayne, 2005; Prest, et al. 2007; Zheng, 2008). Furthermore, hazard map preparation is a very common use of GIS in risk assessment in natural catastrophes such as earthquake risk assessment, hurricane impact risk assessment and environmental risk assessments such as oil spilling at the sea and fire risk assessment modelling at forestry (Sala and Vighi, 2008; Zhang et al. 2009). However, a GIS based system was not developed for use in health and safety risk assessment as a part of daily working plans in linear construction projects.

\subsection{Problem}

Currently, the H\&S personnel performs risk assessment for each construction method and keeps this information attached to the method of statement that is submitted to the owner at the beginning of the project. However, usually site workers and superintendents do not use this risk assessment information at site since it is recorded on based documents which are kept in the office. Also this information is only associated with method of statement, not related with daily individual activities. This results in low awareness in $H \& S$ among workers and engineers and leads to hazards and fatalities at construction sites.

The primary objective of the paper is to develop a GIS based system for H\&S planning as a part of daily work plans and effectively integrating various types of document based H\&S data used in the risk assessment in GIS environment.

The following sub objectives were also achieved in developing this system by means of GIS functionality: (1) Development of the H\&S database in relation with GIS environment, (2)To replace the manual methods to extract the information from the available database and (3) Integrate $H \& S$ risk assessment data with spatial data.

\section{MATERIAL AND METHODS}

\subsection{Proposed System Model}

In the first step of system design, end users need was assessed and information products were described. The information a GIS based DSS generates was described and end users need to be interviewed in order to determine what their job involve and what information they need to perform their tasks.

In the second step the scope of the system was defined and system designed. This phase was performed in three step; conceptual, logical and physical modelling. After that data design was created. In this step spatial and H\&S database design were actualized. Following the data design stage system requirements determining was realized. In this stage examine the system functions and user interface needed along with the hardware and software requirements.
Briefly, users need was assessed, system scope was defined, data design was created, and system requirements were determined in design phase.

The IDEF0 model of the proposed decision support system (DSS) is given Figure 1. To create a risk map of the area, main inputs are the topographic map, site layout plan and the major obstacles identified in the project's construction site such as, other pipelines, power lines. These maps and obstacle information will be integrated to determine potential hazards and health and safety risks according to the H\&S regulations and the project specifications. The final outputs of the system are the risk map that highlights the risk factors and their ratings and proposed mitigation measures to be taken at those high-risk locations (Atay et al. 2010).

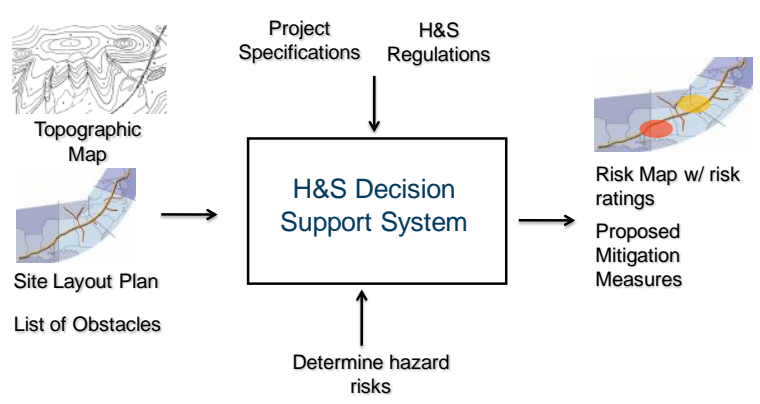

Figure1. IDEF0 model of the proposed H\&S DSS

Currently most commercial Web-based decision support systems are designed around a three or higher tiered architecture. (Yeung and Hall, 2007). Therefore, GIS based $\mathrm{H} \& \mathrm{~S}$ decision support system was developed based on $\mathrm{n}$-tier web based system architecture that is shown in Figure 2.

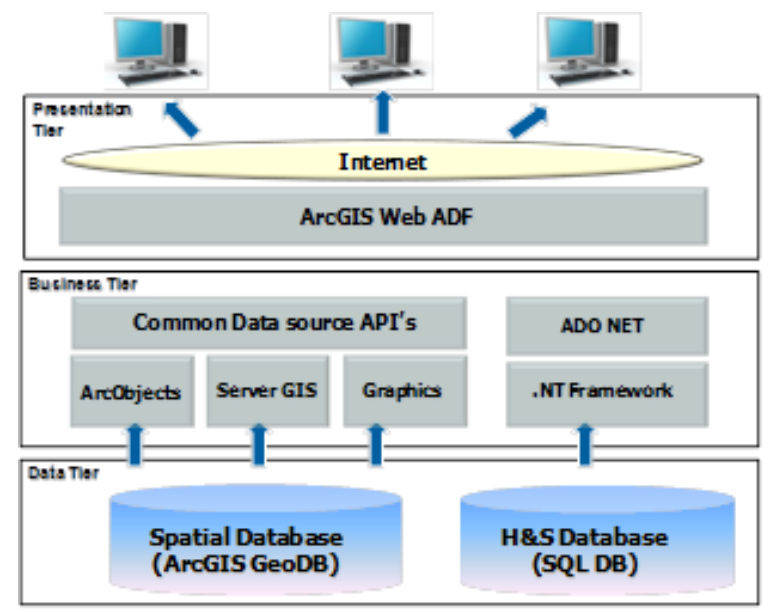

Figure2. System Architecture

Three tier models were chosen for the application which has data tier, business tier and presentation tier (Figure 2). The processes of information storing and retrieving from a database or a file system are executed at data tier. Business tier coordinates the applications, processes commands, implements reasoning mechanisms, makes logical decisions and evaluations and perform calculations. Finally, the main function of presentation tier is to visually present the results to the user.

In the developed system, data tier is composed of H\&S Database and Geo-database. H\&S data is stored on a MS SQL 
server 2008. Furthermore, spatial data is stored as Geo-database file on ArcGIS Server 9.3.1. Spatial queries are executed by using Arc-Object API meanwhile queries that related to $\mathrm{H} \& \mathrm{~S}$, are performed via ADO.NET. Geo-processing, mapping, geometry and geo-data applications are realized via the arc object API at the business layer. Presentation interface is designed by using Asp.NET 3.5 on the Visual Studio 2008 development platform with ArcGIS Web ADF tools and full AJAX solutions.

\subsection{Database Modelling}

$\mathrm{H} \& \mathrm{~S}$ and spatial databases were used independently in solution architecture of system in order to provide integration with other construction management information system.

2.2.1 H\&S Data: It contains activity based risk assessment data. Risk assessment is an essential part of the planning stage of any H\&S management system. It basically evaluates the risks involved in the execution of activities to provide the managers with information necessary to address intervention measures to comply with associated regulations.

Various risk assessment methods, which can be classified as qualitative, quantitative and semi quantitative, may be used depending on the type of risk that is being considered and availability of data about the risk (Grassi et al., 2009; Huges and Ferret, 2007; Rowlinson and Lingard, 2005). In this research study, qualitative method was selected since it is a commonly used for risk assessment in pipeline projects. This method is appropriate where the level of risk does not correspond to the cost involved in applying a more detailed analysis.

To perform a qualitative risk analysis, risk matrix method was used. In risk matrix, risks are rated according to the probability of their occurrence and their possible consequences (Table 1). Ratings can have a scale of three or five while the former is more commonly used. Probability and consequence are rated using verbal descriptors (e.g., medium-frequent probability and major severity) and cross referenced to establish the position of a risk in the matrix (e.g., 1 for low-seldom and 3 for major). These positions indicate the magnitude of the risk (e.g., $2 \times 3=$ 6 , high priority action), which can then be used to guide the selection of appropriate risk control methods and to establish priorities for the implementation of these controls. The greater the magnitude of the risk, the more effort should be put in its control, and the more urgently risk control actions should be implemented.

\begin{tabular}{lll}
\hline $\begin{array}{c}\text { Probability / } \\
\text { Likelihood }\end{array}$ & \multicolumn{1}{c}{$\begin{array}{c}\text { Consequences / } \\
\text { Severity }\end{array}$} & \multicolumn{1}{c}{ Risk Rate } \\
\hline 1- Low & $\begin{array}{l}\text { 1- Slight (off work for } \\
\text { (seldom) }\end{array}$ & 1 - No action \\
2- Medium & 2- Serious (off work & 2- Low priority \\
(frequently) & for > 3 days) & action \\
$\begin{array}{l}\text { 3 - High } \\
\text { (certain or }\end{array}$ & $\begin{array}{l}\text { 3- Major } \\
\text { (death/major harm) }\end{array}$ & $\begin{array}{l}\text { 3-4- medium priority } \\
\text { action }\end{array}$ \\
near certain) & & 6- High priority \\
& & $\begin{array}{l}\text { action } \\
9 \text { - Urgent action }\end{array}$ \\
\hline
\end{tabular}

Table1. Probability, consequence and risk rate values used in the risk matrix
An example of risk rating and mitigation measures is given for trenching activity in Table 2.

\begin{tabular}{|c|c|c|c|}
\hline Hazards & $\begin{array}{c}\text { Associated } \\
\text { Risks }\end{array}$ & $\begin{array}{l}\text { Risk } \\
\text { Rate }\end{array}$ & Mitigation Measures \\
\hline $\begin{array}{l}\text { Unsafe } \\
\text { access, } \\
\text { egress and } \\
\text { falling into } \\
\text { excavation }\end{array}$ & $\begin{array}{l}\text { Injury to } \\
\text { personnel }\end{array}$ & 4 & $\begin{array}{l}\text { - Ladders to be secured } \\
\text { at the top and } \\
\text { extended at least one } \\
\text { meter over the top of } \\
\text { the trench } \\
\text { - Foreman checks the } \\
\text { ladders and barriers at } \\
\text { each shift. } \\
\text { - Barrier excavations > } \\
4 \mathrm{~m} \text { with appropriate } \\
\text { fencing }\end{array}$ \\
\hline
\end{tabular}

Table2. An example of risk rating performed for trenching activity based on the H\&S standards

In the proposed system, the hazards were extracted from $\mathrm{H} \& \mathrm{~S}$ regulations, formalized and stored in database as interoperable with the GIS system. During the formalization of the hazard data, it was identified that there are two types of hazards: (1) Hazards which have risk ratings that are independent of projects, for example, a hazard that is related to breaking down of a stone crusher has a fixed risk rating, regardless of the project and location, (2) Hazards which have risk ratings that change based on project characteristics. Hazards that are dependent on the project characteristics are also grouped into two categories: (1) Spatial hazards, which can occur if some spatial characteristics exist, (2) non-spatial hazards, which are independent of spatial characteristics.

2.2.2 Spatial Data: There are two fundamental approaches for representation of spatial data; vector model and raster model. In this paper study spatial analysis based H\&S risk assessment study is addressed. The vector model allows us to represent specific spatial locations explicitly and provides the precise position of features in space. Based on analytical geometry, a vector model builds a complex representation using primitive objects such as points, lines and areas. The raster data model quantizes or divides space as a series of packets or units, each of which represents a limited, but defined amount of earth's surface. The raster model divides the earth into rectangular building blocks as grid cells or pixels that are filled with the measured attribute values. The location of each cell or pixel is defined by its row and column numbers. If the reasoning mechanism for identifying a spatial hazard is based on geographic objects represented by points, lines and polygons on the map (e.g., roads, underground cables), related hazard was represented in a vector model. The hazards that needs to be defined based on slope and altitude were represented in a raster model since they are associated with heights which is represented in raster data format in GIS.'

In the study geometric data was generated from 1:5.000 scaled topographical maps and 1:5.000 scaled pipeline layouts which are two fundamental resources for pipeline construction projects. These data resources are shown on Figure 3. and Figure 4. With respect to HS risks, relevant to terrain, are determined by spatial terrain analysis. Therefore it is based on raster data and its derived forms like height and slope data. Derived raster data and its source shown on Figure 6. 


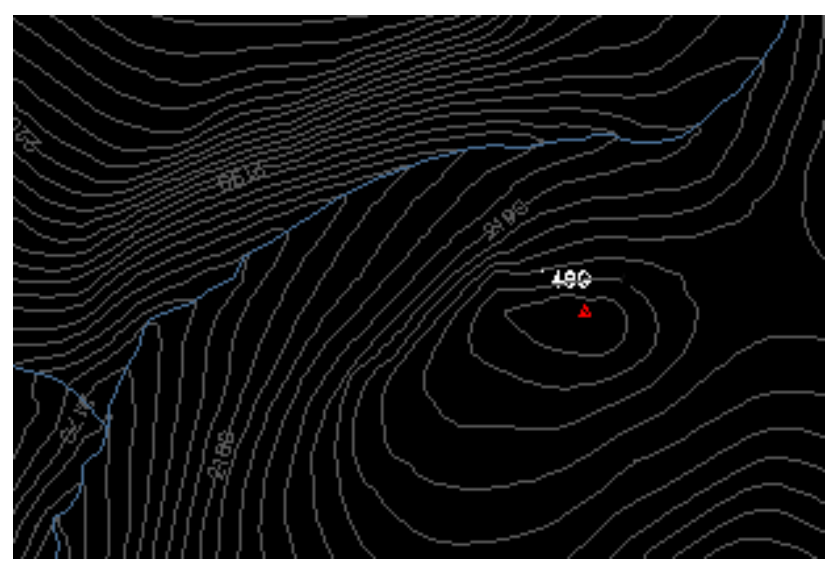

Figure3. 1:5.000 Scaled Topographical Map

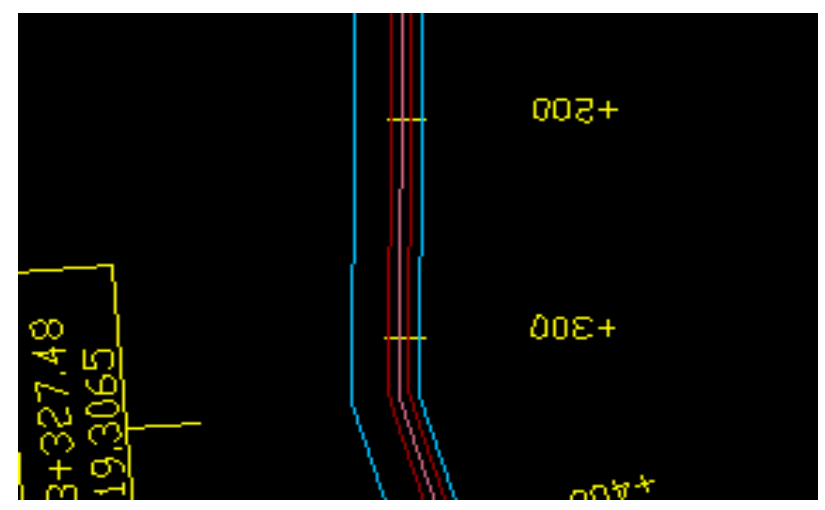

Figure4. 1:5.000 Scaled Pipeline Layouts

Obstacle lists of pipeline prepare at design stage of projects and contain information regarding spatial objects that has intersection with pipeline axis like overhead power line and underground cables. These lists have coordinates of objects, owners' information and material etc. In this research pipeline obstacle list has been used as attribute table of spatial data and is given Figure 5 .

\begin{tabular}{|c|c|c|c|c|c|c|c|c|c|c|}
\hline Ulame & KP & Easting & Morthing & Elevation & | Owner & Material & Type & Radius & | Clearance & Voltage \\
\hline NG4-014 & eNulls & 4090.891 & 8103.154 & 160.648 & ANulls & ANulls & ENull:s & eNull:s & ENulls & Nulls \\
\hline NG5-903 & 3517.16 & 564160.2 & 02.487 & 129.577 & Nulls & ANulls & envulls & eNull: & eNulls & ENulls \\
\hline SKG4.906 & 2253.5 & 4112.692 & 65.08 & 196.151 & DSI & BETON & Trapez & eNulls & eNulls & eNulls \\
\hline NG4-015 & 4343.37 & 4451.789 & 39.9 & 78.216 & ANulls & ENulls & envulls & ANulls & eNulls & ANulls \\
\hline 64-176 & 8639.48 & 7140.691 & 0.19 & 999.279 & A ANulls & ANulls & eNulls & eNulls & \&Null» & eNulls \\
\hline SKG4.951 & 13370.14 & 7914.221 & 6168.44 & 810.251 & DSI & BETON & Trapez & ANulls & eNull: & ANulls \\
\hline G3-951 & 13423.95 & 7888.142 & 21.76 & 809.624 & ANulls & ANulls & ANulls & ANulls & eNulls & eNulls \\
\hline NG2-016 & \begin{tabular}{|l|}
13458.71 \\
\end{tabular} & 7871.51 & 6091.233 & .752 & ANulls & ANulls & ANulls & eNulls & envulls & ANulls \\
\hline 3-071 & 14699.16 & 7341.892 & 003.781 & 968 & ANulls & ANulls & envulls & eNull: & envulls & ENulls \\
\hline NG3-952 & 14819.01 & 7371.65 & 87.829 & 10.246 & ANulls & ANulls & anull: & eNulls & enulls & aNulls \\
\hline YBG1-001 & 9419.04 & 7531.991 & 92.9 & 139 & TEDAS & ANulls & eNulls & 40 & envulls & eNulls \\
\hline YG5-244 & 73.28 & 4149.472 & 43.489 & 85.393 & KHGM & ANulls & eNulls & eNulls & enulls & eNulls \\
\hline YG4.015 & 1149.9 & 28. & 9.7 & 688 & KHGM & eNulls & eNulls & eNulls & eNull:s & Ulls \\
\hline YG4-017 & 2019.7 & 4124.534 & 086.965 & 210.365 & KHGM & ANulls & ANulls & eNulls & enulls & eNulls \\
\hline $65-904$ & 1598. & 4222 & 95.0 & 242.529 & KHGM & ENull: & sNulls & eNull: & ENull: & ENulls \\
\hline YG6-905 & 4913.37 & 4712.756 & 51.4 & 59.717 & KHGM & ANulls & ENull: & ANulls & enulls & eNulls \\
\hline G4-018 & 5030.58 & 4833.71 & 7.44 & 301 & KHGM & eNulls & Nulls & endulls & enulls & ANulls \\
\hline YG6-019 & 5082.39 & 63.535 & 3229.0 & & KHGM & aNulls & ANull: & ANull: & enull: & Nulls \\
\hline YG6-906 & 7593.48 & 6615.043 & 1457.028 & 24.563 & KHGM & eNulls & eNull: & eNulls & eNulls & ENulls \\
\hline
\end{tabular}

Figure5. Pipeline Obstacle List Sample

\subsection{Reasoning Mechanism}

The reasoning mechanism developed for identification of hazards automatically by the system by using project topography and layout maps, is based on automatically execution of spatial queries and spatial analysis. Furthermore reasoning mechanism for identifying a spatial hazard is based on geographic objects represented by points, lines and polygons on the map (e.g., roads, underground cables); related hazard was represented in a vector model.

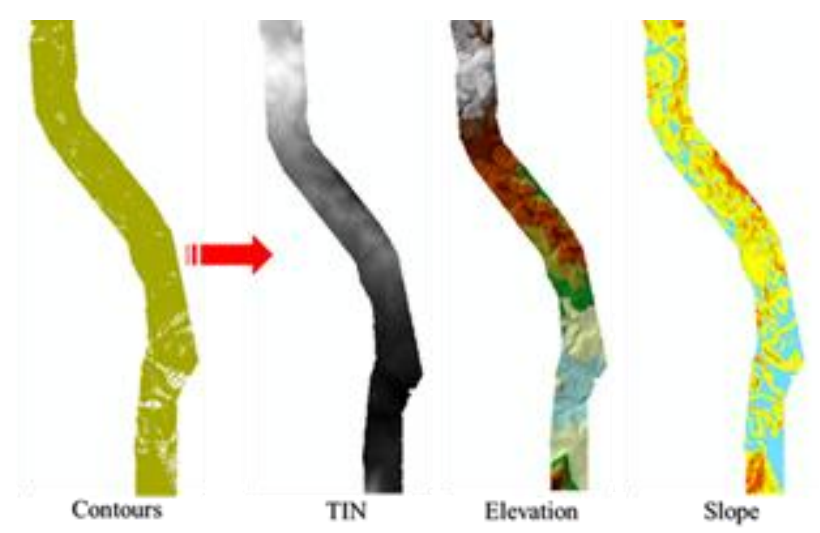

Figure6. Derived Raster Data

The hazards that needs to be defined based on slope and altitude were represented in a raster model since they are associated with heights which is represented in raster data format in GIS. Derived data shown in Figure6 is used to determine hazards relevant to terrain. Moreover used analysis methods are given below Table2.

\begin{tabular}{lc}
\hline \multicolumn{1}{c}{ Spatial Analysis } & \multicolumn{1}{c}{ Functions } \\
\hline $\begin{array}{l}\text { Linear Referencing } \\
\text { Dynamic }\end{array}$ & $\begin{array}{c}\text { - to define working interval on } \\
\text { pipeline, }\end{array}$ \\
& $\begin{array}{c}\text { - to determine and model hazards } \\
\text { relevant to heights (i.e. working } \\
\text { and travelling to height etc.) }\end{array}$ \\
Height Analysis & $\begin{array}{l}\text { to determine and model hazards } \\
\text { relevant to slope (i.e. equipment } \\
\text { using on steep slopes etc.) }\end{array}$ \\
Slope Analysis & $\begin{array}{l}\text { to determine and model hazards } \\
\text { relevant to centerline (i.e. access } \\
\text { egress to trench etc.) }\end{array}$ \\
\end{tabular}

Table2. Spatial analysis and functions to be used

Regarding hazard risk assessments', whose data are stored in the system, is performed in three steps: (1) The risks ratings for project-independent hazards are entered by the system developer/H\&S personnel only once as default values, and these ratings are used for all pipeline projects, (2) The risk ratings for non-spatial and project dependent hazards are entered by the $\mathrm{H} \& \mathrm{~S}$ personnel at the beginning of each project, (3) the risk ratings for project dependent and spatial hazards are automatically identified by the system by using project topography and layout maps and presented to the user.

According to H\&S DSS work flow as shown in Figure 7., once the risk ratings are created, a worker or a project engineer, can enter the location of the activity in the system (e.g., between 10$15 \mathrm{~km}$ ) and enter the type of activity that s/he will perform in that area (e.g., trenching). The system will provide a thematic risk map where different risk ratings are shown as colour-coded areas along with the proposed mitigation measures. For instance 
working near rivers and water deeper than 3 meters has drowning risks. In order to eliminate this risk, it is necessary to monitor heavy sudden rainfall that can cause sudden increase of river level and some precautions are taken near the river. System finds and highlights the rivers and water resources which are deeper than $3 \mathrm{~m}$ on the map, and pinpoints the associated risks of hazard and mitigation measures. By using the proposed system, managers, superintendents and workers will become aware of the risks; participate in $H \& S$ activities by taking necessary measures based on the risk ratings.

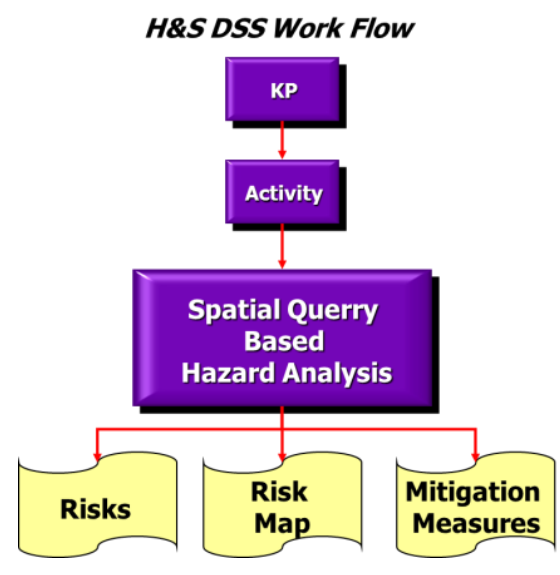

Figure7. H\&S DSS Work Flow

\subsection{Implementation}

Case study was focused on $17 \mathrm{~km}$ of a pipeline project. It was formed by steel pipe, has 30 meters working strip and located at mountainous terrain. System was developed to produce risk map for each activity that has been performed in pipeline construction such as clearing and grading, trenching, stringing etc. $H \& S$ regulations was used in the system for implementing H\&S DB these are Health and Safety at Work etc Act 1974 and Management of Health and Safety at Work regulations 1999

User selects the activity and enters working area beginning point and end point from user interface as shown on Figure8.

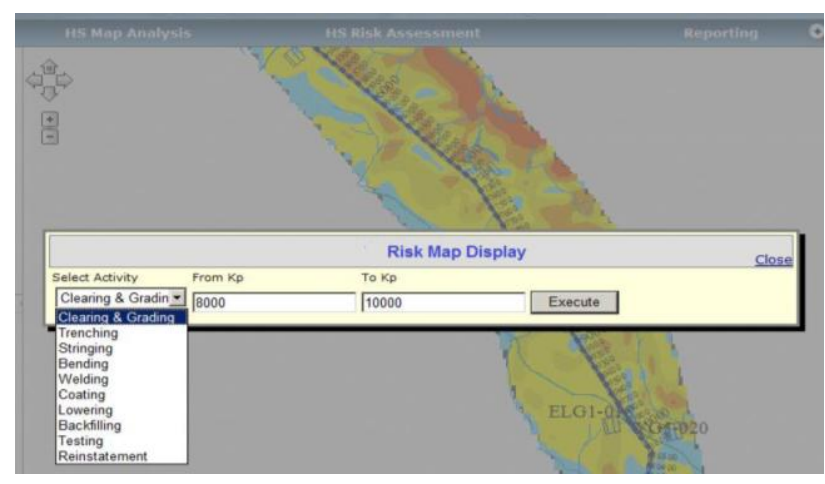

Figure8. User Interface for Information Entry

Execute the button, risk map will be shown. For example on this map hazard are highlighted by this system, based on the risk score (Figure9.).

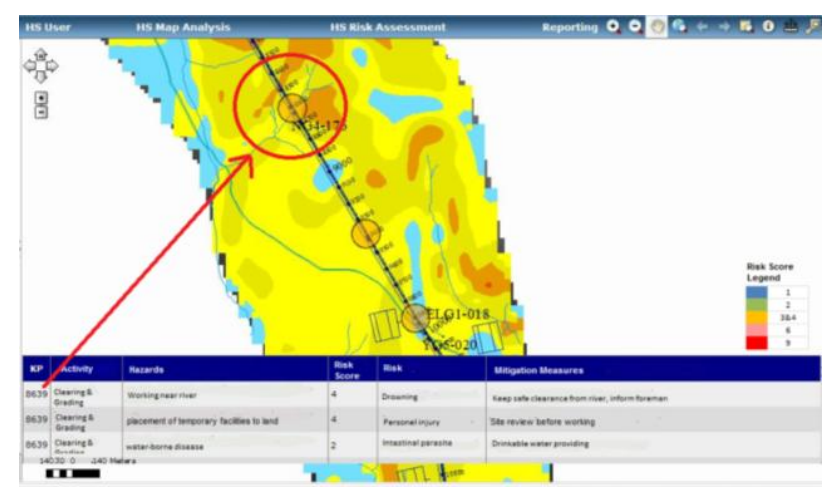

Figure9. User Interface Viewing the Hazards \& Risk Map

\section{CONCLUSION}

This paper describes an on-going study that focuses on design and development of a web-based health and safety decision support system integrated with GIS for oil and gas pipeline construction projects. H\&S DSS can be used for detecting potential hazards and risks, more importantly, as a warning sign for the construction activities that require immediate corrective action for mitigation. It allows the user access the $\mathrm{H} \& \mathrm{~S}$ data efficiently for effective decision making and proactive $H \& S$ management.

The proposed system provides integration of spatial and thematic information in a single environment. Spatial data was retrieved from construction layout plans and topographic maps of the project. Geography-related hazardous work activities and mitigation measures were extracted from British Health and Safety at Work Act and Construction (Health, Safety and Welfare) Regulations and formalized. This formalized H\&S data was entered to a database in GIS and represented in several data layers. Once the user input is collected for non-spatial risks, the database was queried for potential hazards and the work areas that had hazard potential and safety risks were identified. Moreover information about mitigation measures was retrieved to take necessary actions for preventing construction accidents. Besides, pinpointing potential hazards and their locations at construction site it also offers mitigation measures.

It is anticipated that the system can facilitate an effective H\&S management with high level participation of employees. Since it is a web-based system, it enables remote access and control, which is important for linear projects that have a scattered nature. In the future, the developed $H \& S$ system can be integrated with construction management software.

\section{REFERENCES}

Atay, H., Ergen, E., Toz, G., 2010. GIS based decision support system for health and safety management in linear projects, Proceedings of The International Conference on Computing in Civil and Building Engineering, Nottingham, UK.

Bansal V.K. and Pal M., 2005. GIS in Construction Project Information System. Proceedings of Map India, 8th Annual International Conference and Exhibition in the Field of GIS, GPS, Arial Photography, and Remote Sensing. New Delhi, India. 
BLS, U.S. Bureau of Labor Statistics, 2009. U.S. Department of Labor, Washington D.C, Available online: www.bls.gov, Last accessed: December 2009

Clark, K., 2001. Getting Started with Geographic Information Systems. Prentice Hall, NJ.

Everett, J.G., Frank, P.B., 1996. Cost of accidents and injuries to the construction industry. J. Constr. Eng. Manag., ASCE 122 (2), pp.158-164.

Grassi, A., Gamberini, R., Mora, C., Rimini, B., 2009. A fuzzy multi-attribute model for risk evaluation in workplaces. Safety Science Journal, 47, pp. 707-716.

HSE, 2009. Work-related injuries and ill health in construction in 2008/09, Technical Report, London, UK

Hughes, P., Ferret, E., 2007. Introduction to Health and Safety in Construction. Butterworth Heinemann Publications, UK.

Kartam N.A., 1997. Integrating safety and health performance into construction CPM. Journal of Construction Engineering and Management, ASCE, 123, pp. 121-126.

Kartam, N.A., 1997. Integrating safety and health performance into construction CPM. J. Constr. Eng. Manag., ASCE 123(2), pp.121-126.

Lo C.P. and Yeung A.K.W., 2002. Concept and Techniques of Geographic Information System. Prentice-Hall of India, New Delhi.

Luettinger, J., and Thayne, C., 2005. Geographic Information System-based Pipeline Route Selection Process, J. of Water Resour. Plng. and Mgmt., 131(3), pp. 193-200

Mohamed, S. 2003. Scorecard Approach to Benchmarking Organizational Safety Culture in Construction, J. Constr. Eng. Manag., 129(1), pp. 80-87.

Prest, R., Daniell, T., and Ostendorf, B., 2007 Using GIS to evaluate the impact of exclusion zones on the connection cost of wave energy to the electricity grid. Energy Policy, 35(9), pp. $4516-4528$

Rowlinson, S., Lingard, H., 2005. Occupational health and safety in construction project management. Spon Press, UK.

Sala, S., Vighi, M., 2008. GIS-based procedure for site-specific risk assessment of pesticides for aquatic ecosystems. Ecotoxicology and Environmental Safety, 69(1), pp. 1-12

Salminen, S., 1995. Serious occupational accidents in the construction industry. Constr. Manag. Econ. 13, pp. 299-306.

Saurin, T.A., Formoso, C.T., Guimaraes, L.B.M., 2004. Safety and production: an integrated planning and control model, Constr. Manag. Econ., 22, pp. 159-169.

SGK, 2007. Occupational Accidents in 2006 (in Turkey), Social Security Institution, Ankara, Turkey.

Yeung, K.W.A., Hall, G. B., 2007. Spatial Database Systems, Design, Implementation and Project Management, Springer, Netherlands.
Zhang, J., Liang, J., Liu, X. P., Tong, Z. H., 2009. GIS-Based Risk Assessment of Ecological Disasters in Jilin Province, Northeast China. Human and Ecological Risk Assessment: An International J., 15, pp. 727-745.

Zheng, M. B., Guo-Hua C.J., Gongcheng, S., 2008. Study on 3D simulation of gas-pipelines applying ArcGIS. Computer Engineering and Design Journal, 29(7), pp. 1824-1827. 